\title{
Emergency Department Nurses Changing Roles and Boundaries: Narratives of Burnout
}

\author{
Debbie Hetherington*, Nathan J Wilson, Kathleen Dixon and Gillian Murphy \\ School of Nursing and Midwifery, Western Sydney University, Australia
}

*Corresponding author: Debbie Hetherington, School of Nursing \& Midwifery, Western Sydney University, Australia.

Received Date: February 26, 2020

Published Date: April 15, 2020

\section{Opinion}

Health and nursing literature states that Australian nurses are exposed to ongoing stressful work situations and that those working in emergency departments are faced with a unique stressor: traumatic emergency cases WHO (World Health Organization) 2019 [1]. Constant exposure to such stressful events presents the potential for the emergency department nurse to develop emotional response mechanisms that run counter to their professional identity as a nurse, such as a loss of compassion towards others, as one way to cope. Exposure to ongoing stress at work may result in burnout, which has been defined as a condition that is the result of chronic workplace stress that has not been productively managed WHO 2019 [1]. There is growing research relating to burnout in hospital settings [2-4], however, research about burnout specific to nurses who work in the emergency department is scant. With reported retention rates among emergency nursing staff decreasing, it was time to focus on this nursing cohort to explore the challenging issues they face at work. Additionally, this research explored how these challenges directly and/or indirectly affected their personal and private lives [3].

Qualitative research methods are valuable in providing indepth explanations of complex experiences and understanding unexpected and unique events and experiences. This method was selected as the literature review identified a significant gap in the area of burnout and emergency department nurses' experiences particularly in Australian emergency department nurses. These nurses have not been previously asked to discuss burnout, nor explicitly seeking their experiences about what it means to them and/or how they are affected. This unexplored area required a narrative approach, using the emergency nurses' own thoughts and words, to gain insight into their experiences of burnout and how it had shaped their lives.

\section{Acknowledgement}

None.

\section{Conflict of Interest}

No conflict of interest.

\section{References}

1. (2019) World Health Organisation. Mental Health: Mental health evidence and research.

2. Adriaenssens J, De Gucht V, Van Der Doef M, Maes S (2011) Exploring the burden of emergency care: Predictors of stress-health outcomes in emergency nurses. J Adv Nurs 67(6): 1317-1328.

3. Hunsaker S, Chen HC, Maughan D, Heaston S (2015) Factors that influence the development of compassion fatigue, burnout, and compassion satisfaction in emergency nurses. J Nurs Scholarsh 47(2): 186-194.

4. Maslach C (2001) What have we learned about burnout and health? Psychol Health 16(5): 607-611. 